\section{NON SOLTANTO PAROLE: LAS MÁSCARAS DE MINA}

NON SOLTANTO PAROLE: MINA'S MASKS

José Luis Espinosa UAB Idiomes

Resumen:

Abstract:

El título de este artículo forma parte de una de The heading of this article is part of one of las canciones más conocidas de Mina Mazzini, the most well-known songs by Mina Mazzini, Parole, parole. Mina siempre ha marcado Parole, parole. Mina has always set trends. tendencia. Luciano Tallarini contribuyó a crear Luciano Tallarini contributed to create her su imagen en las portadas de los discos. En el image on the covers of the discs. In this study siguiente estudio se analizará la trayectoria the career of the Italian artist will be analysed de la artista italiana desde sus comienzos más from her most remote beginnings.

remotos.

\section{Palabras claves:}

Mina, canción, Tallarini.
E rido per lo scherzo che tu m'hai giocato,

poi guardo nello specchio l'effetto se è riuscito

E poi con impudenza ti chiuderò la bocca

$$
\text { e parlerò per te... }
$$

(Franz; Ti conosco mascherina, 1991)

Parole, parole, parole. Parole, parole, parole...Parole fra noi. Este es seguramente uno de los estribillos más internacionalmente conocidos de Mina. Interpretada originalmente junto al actor Alberto Lupo, la canción ha conocido diferentes versiones y ha sido interpretada por la misma Mina en diferentes idiomas, por no hablar de las versiones que otros artistas han hecho del tema. Pero no sólo de parole ha vivido - y vive - la carrera de Mina. Y esa es la cuestión en la que me voy a centrar. De todos es sabido que, tras su retiro de los escenarios en 1978, a excepción de pequeñas apariciones televisivas a finales de los '70, Mina no ha vuelto a cantar en directo ni a conceder entrevistas a los medios; en cambio ha continuado grabando música y publicando regularmente discos, convirtiéndose en una de las cantantes del mundo que puede presumir de una discografía más vasta y, desde luego, en la única que lo ha conseguido desde su exilio voluntario. Y es que la sombra de Mina es alargada y, aun así, en estos treinta y tres años de ausencia de los escenarios son muchos los números uno y los primeros puestos en las listas de ventas de álbumes que se han sucedido casi cada vez que ha visto la luz un nuevo trabajo, esquivando los embistes de la industria discográfica y, me atrevería a decir, riéndose de ella en muchos casos. Nadie duda de la calidad vocal de la cantante, ni tampoco de su inteligencia y personalidad. Y este binomio es el que sigue dando éxitos a Mina porque, ¿cómo es posible, en la era de la imagen, que una cantante de setenta años se cuele en los primeros puestos de las listas de ventas y del airplay cada vez que su voz se asoma a las ondas? Sin duda, creando una imagen una especie de alter ego impreso, que ella misma y sus brillantes colaboradores se han encargado de nutrir y cuidar como se hace con las flores delicadas.

\section{CANTAR O GRITAR: URLATORI E URLATRICE}

Mina Mazzini nació - como ella misma dice, por error o casualidad - en Busto Arsizio (Varese, Lombardía) el 25 de marzo de 1940. Su familia vivía en Cremona, allí se crió y es la ciudad que le dio posteriormente su famoso apodo, la tigre di Cremona. Sus inicios en el mundo de la música se remontan a mediados de los años '50, cuando, todavía adolescente y con el apoyo de una familia de músicos - su padre y su hermano trabajarán con ella - empieza a presentarse en diferentes locales de música en directo cantando sus propias versiones de éxitos del rock anglosajón del momento bajo el pseudónimo de Baby Gate. No tardarán en notarla los discográficos del momento y, a finales de 1958 se publican sus primeros 45 r.p.m para Ri-Fi Records. 
El año 1959 es considerado como el del inicio de su carrera y los medios empiezan a hacerse eco de esta nueva voz estridente que se une al grupo de lo que en la época la crítica llamaba los urlatori, apodo despectivo para toda esa generación que se hizo un hueco en la música italiana cantando en inglés, primero, y versionando después en italiano los éxitos del momento. No se trataba más que de un grupo de cantantes emergentes - Tony Dallara o Peppino di Capri entre los primeros - que representaban un nuevo modo de entender la música frente al tradicionalismo de la canción italiana más canónica que estaba representada por voces como las de Claudio Villa o Nilla Pizzi. Ese mismo año, Mina aparecerá por primera vez en televisión en el programa Lascia o raddoppia? de Mike Bongiorno y participará además en la película Juke Box - Urli d'amore. Un año después, se estrenará Urlatori alla sbarra, dos películas musicales - musicarelli, los llamaban - pensadas para el lucimiento de esta nueva generación musical de la que nacieron otras importantes figuras como la de Adriano Celentano. Efectivamente, a partir del año 1960, la carrera de Mina sube como la espuma. Deja de lado el rock y comienza a cantar composiciones de autores italianos; el primer gran éxito llegará con Il cielo in una stanza, tema que el entonces casi desconocido Gino Paoli había compuesto para sí mismo, que llegó al número 1 el 2 de agosto de 1960 y permaneció allí durante once semanas consecutivas. La urlatrice empezaba a dejar paso a la Voz y, con ella, la gran popularidad, musical y televisiva, de la década sucesiva.

\section{MINA: ICONO DE LA MODERNIDAD}

La Mazzini es una mujer que ha ido siempre por delante de su tiempo y marcando tendencia. Y es curioso porque, probablemente, nunca lo pretendió. Fue la primera artista que se presentaba en público no como una mera estatua cantante, sino como una artista que ponía en escena lo que cantaba: Italia enloquecía con sus peculiares movimientos de manos y sus cambios de peinado, que se convertirían en marca de la casa, sus cejas pintadas marcaron tendencia en la época, los lunares que aparecían y desaparecían de su rostro causaban furor. De alguna manera, representaba la libertad artística en un entorno cultural aún encorsetado.

Pero esa libertad no fue gratuita. En el año 1962 anunció que esperaba su primer hijo junto a su pareja, Corrado Pani, un famoso actor que todavía estaba casado con su anterior mujer. El escándalo fue tal que le supuso el ostracismo televisivo durante un año, justo el tiempo que el público italiano pudo soportar su ausencia, antes de pedir a gritos que volviera a los escenarios. El 10 de enero de 1964 reaparece en la televisión en el programa La fiera dei sogni, al que de nuevo Mike Bongiorno invitará. El regreso fue triunfal, y así fue su carrera televisiva hasta que ella misma decidió desaparecer y convertirse en una máscara con voz.

\section{REPRESENTAR, ILUSTRAR, DIBUJAR A MINA: LAS MÁSCARAS}

Como comentábamos antes, es difícil crear la imagen de alguien - especialmente si se trata de un artista, para quienes la imagen es fundamental - cuando al artista en cuestión no le gusta exponerse demasiado al público. Y eso, en el caso de Mina, ha sido siempre una constante. En 1967, Giacomo Mazzini, el padre de la cantante, abre PDU, la discográfica que, desde ese momento, iba a gestionar su carrera musical, y contrata a un fotógrafo de cierto nombre en la profesión, Luciano Tallarini, como director de comunicación. Tallarini será desde ese momento y hasta 1984, el encargado de las portadas de los discos de Mina, con la ayuda inestimable del dibujante Gianni Ronco. En 1973 se unirá al grupo Mauro Balletti, que continua trabajando hoy en día para la cantante. Estos tres nombres son los autores de la ingente cantidad de instantáneas y dibujos que componen el imaginario colectivo del público de Mina y los culpables, por lo tanto, de que un disco de la cantante se reconozca a kilómetros de distancia. Y, para ello, han utilizado a lo largo de cuatro décadas algunos elementos muy sencillos - el pelo, los ojos, la nariz, los lunares, las manos - convirtiéndolos en señas inequívocas de identidad. Lo comentaremos a partir de algunas de las portadas más significativas de los últimos cuarenta años.

\subsection{Los años ' 70}

El primer trabajo de Luciano Tallarini para PDU fuela portada delálbum Canzonissima '68, para la que utilizó una foto del archivo que había conseguido recopilar fotografiando a la cantante en diferentes backstages de la televisión, dado que no era muy fácil convencer a Mina para más reportajes fotográficos que los que sus contratos televisivos y publicitarios le exigían. Así que siguió esa estrategia, trabajando a partir de las fotos que le iba haciendo a la cantante, hasta que en 1971, a punto de publicarse el disco Mina, surgió un problema: la cantante estaba embarazada de su hija Benedetta y, Tallarini, que la conocía bien, le propuso una serie de fotos de cachorros de animales. A Mina le encantó la idea y eligió la foto de un cachorro de chimpancé. De ahí la portada del disco conocido por sus fans como quello della scimmia.

Tallarini consiguió por fin un reportaje ad hoc para los dos discos que Mina publicó en 1973, Frutta e verdura y Amanti di valore. El pelo corto, rizado y platino que la cantante lucía en las diferentes fotos que componen ambas portadas arrasó en las peluquerías del momento. Y fue también el inicio del concepto dual - la publicación de discos dobles o de parejas de discos - que sería una constante en la discografía de Mina a partir de ese momento. En efecto, el año siguiente, 1974, nace un nuevo proyecto doble; por un lado, se trataba de publicar un álbum de homenaje a las canciones americanas con las que Mina había dado sus primeros pasos como Baby Gate, y por otro, un nuevo álbum de canción “italiana". El resultado fue los geniales BabyGate y MinaR, para los 
que Tallarini ideó unas imágenes muy años '20, con una Mina muy pin up y un cocktail en la mano para el disco americano y un panino di salame para el disco italiano, por aquello de la marca registrada que sugería el título. Dos años más tarde, en 1976, se publica el binomio Singolare / Plurale. Singolare es una colección de diez temas originales donde aparece la Mina más auténtica, de ahí que Tallarini, por única vez, ponga a la cantante, sonriente, en primer plano. Plurale es el complemento del disco anterior; se trata de un disco de versiones - como hará Mina a menudo, alternar en un proyecto o a distancia de pocos meses un álbum de temas inéditos y otro de versiones - que posee la característica de que todas ellas, que van de los Beatles a Duke Ellington, están arregladas para varias voces, interpretadas todas ellas por la propia cantante. Para mantener la unidad del proyecto, Tallarini pone de nuevo en portada a la cantante, en una foto del mismo reportaje, muy similar a la del disco Singolare, donde la cantante aparece, esta vez, cubriéndose media cara con la mano izquierda, metaforizando de alguna manera el desdoblamiento vocal del disco. Originalmente el disco se publicó como un doble vinilo en el que había como regalo un póster de la misma sesión donde Mina muestra una mano con seis dedos. Pero, como ocurrió con otros discos de la cantante, se imprimió posteriormente en dos volúmenes.

$Y$, si damos un salto de tres años, nos acercamos al final de la década con un nuevo hito en la discografía de la cantante: los dos volúmenes de Attila, que se publicaron inicialmente de manera conjunta en 1979 y en cuya portada aparece la cabeza de una Mina dibujada calva, en tonos grises, con los ojos en blanco y la boca manchada de colores tras haber mordisqueado un helado cuyos restos vemos bajo su barbilla. La portada y el título se deben a un proyecto de cierta agresividad musical, que supone el paso a una década de transición de sonidos, como fueron los '80. Para la posterior versión que se publicó en dos volúmenes - es la que se encuentra actualmente en formato digital - se eligió otra imagen con la misma estética donde Mina aparece de cuerpo entero sentada en una silla y sujetando un molinillo de viento de colores. Sigue estando calva y con los ojos en blanco. Las imágenes de Attila fueron de un impacto tal que llegaron a formar parte de una exposición sobre diseño gráfico italiano en el MoMA de Nueva York.

\subsection{Los años ‘ 80}

A Mina le gustaba la idea de titular Attila este proyecto y le encantó la propuesta de Tallarini para el grafismo, hasta tal punto que le propuso, para el siguiente, realizar algo donde se la viera completamente llena de pelo. Así nació el título y la portada de Salomè en 1981, donde encontramos a la cantante representada como la mujer barbuda. 1983 es el año de la despedida de Tallarini, cuyo último trabajo para PDU fue el diseño del doble álbum Catene, donde vemos a una doble Mina, enfrentada a sí misma e inspirada en la película $M$, el vampiro de Düsseldorf de Fritz Lang. A partir de ese momento, la responsabilidad gráfica de los proyectos musicales cayó en manos de Mauro Balletti, que sigue siendo todavía hoy el artífice de la imagen discográfica de la cantante. Y siguieron llegando imágenes para hacer historia. En 1987 se publica Rane Supreme, un nuevo doble disco - versiones e inéditos - cuya portada es quizá junto a Attila, el punto álgido de la agresividad mazziniana. A pesar de tratarse de un disco relativamente suave, a Mina le gustó la propuesta de Balletti de hacer un fotomontaje poniendo su cara, enmascarada, en el atlético cuerpo de un hombre culturista; se abría así un nuevo tema en la forma de ilustrar a la cantante: el cuerpo.

Mucho se hablaba en esa época de las razones por las que Mina no aparecía en público. Casi nadie había creído, diez años antes, que ese retiro anunciado fuese serio y definitivo. Las drogas, los problemas con el fisco italiano, el sobrepeso... La respuesta de Mina llegaba siempre en forma de canciones y portadas y en 1989 publicó el doble Ridi Pagliaccio, parafraseando el aria más conocida de la ópera I Pagliacci de Ruggero Leoncavallo y apareciendo en su portada con la imagen más al estilo drag queen que encontramos en su discografía, pintada como una puerta, si se me permite el coloquialismo, y esquivando una tarta de cumpleaños que alguien intenta lanzarle a la cara y que se trata en realidad de un sombrero. El cuerpo y el cabello vuelven a aparecer en uno de los proyectos quizá más crípticos, Uiallalla, que cierra la década y nos presenta un supuesto árbol genealógico de Mina, con retratos en color sepia y acompañada de otras dos mujeres - ¿su madre y su abuela?- que no son sino dos hombres travestidos. Es la Mina que, por un lado, se insiere en la tradición pero que, por otro, intenta escapar de ella.

\subsection{Los años ‘ 90}

El cuerpo y la dualidad vuelven en los dos álbumes que inauguran la nueva década, Ti conosco mascherina en 1990 y Caterpillar en 1991. Con ambos se abre un nuevo momento de esplendor musical en la discografía de Mina. La portada y la selección de títulos del primero de ellos es ya toda una declaración de intenciones. Mauro Balletti dibujó a una Mina de inspiración picassiana, que en la imagen principal del disco nos aparece en versión doble, con un alter ego con el que se funde y confunde como si se tratara de dos hermanas siamesas. Esta idea, unida al título, que en español sería algo así como "te conozco bacalao..." nos da la idea del contenido brillante del disco: una colección de versiones que van desde Caruso de Lucio Dalla o la Malafemmena de Totò a Billy Jean de Michael Jackson, unida, como de costumbre, a algunas nuevas canciones que dan una vuelta de tuerca a la Mina de los ochenta, abriéndose a nuevos sonidos, a nuevas canciones que suponen aire fresco después de la difícil década de los ochenta que, en el caso de Mina, fue riquísima en diseño gráfico pero muy de transición en el 
aspecto musical. Caterpillar es una nueva declaración de intenciones; es un disco de bombas musicales; de grandes canciones - y grandes revisiones - en el habitual primer disco de versiones y de grandes canciones también en el disco inédito. Para presentar el proyecto, Balletti puso en portada el dibujo, salido de la irónica pluma de Gianni Ronco, de una Mina tremendamente gorda - como una apisonadora - que se estira el pelo - de nuevo, larguísimo, el pelo.

Un año después, llegamos a otro de los discos históricos; en Sorelle Lumière, de 1992, se produce un nuevo homenaje al cine ya desde el título y vemos en la carátula el perfil, inconfundible, de Mina fundida en un proyector cinematográfico y que presta sus ojos a la proyección. La portada de Balletti consiguió el premio de los publicistas italianos a la mejor imagen del año. Y, si hablamos de máscaras, 1993 es un año especialmente rico. Mina publica dos proyectos; en primer lugar su particular tributo temático a los Beatles, Mina canta I Beatles, para el que Mauro Balletti creó una composición de caras de la cantante homenajeando la mítica portada del álbum Revolver de los de Liverpool. En segundo lugar, se publicó el doble álbum de turno, titulado Lochness, en el que Mina aparece quitándose una máscara metálica que está, a su vez, desapareciendo, como convirtiendo al monstruo en mujer. Pero demos un nuevo salto en el tiempo. En 1995 Mina cierra su tradición de álbumes dobles con el fantástico Pappa di latte, cuya portada es la imagen de la cantante enmarcada en una galleta, vestida con un típico mantel de trattoria y peinada con una gran melena compuesta por todo tipo de pasta, y en 1996 abre una nueva era de discos individuales homenajeando a su ciudad. En la portada de Cremona, la vemos vestida por Gianni Versace, fotografiada como siempre por Balletti y fotomontada en la mítica Piazza del Comune de su ciudad. 1997 nos trae Leggera, un nuevo disco aunque, de alguna manera iniciático. Mina sigue investigando sonidos y actualizándose constantemente y realiza este álbum de clara intención pop con algunos de los nombres más interesantes de la escena musical italiana e internacional del momento: Audio 2, Le voci atroci e incluso Mick Hucknall, líder del grupo británico Simply Red. La elección de Balletti no podía ser otra: un nuevo fotomontaje donde vemos la cara de Mina extenuada en el cuerpo de una atleta que llega - ligera - a la meta, tras una carrera.

Otro hito de los'90 y de la carrera de Mina fue el reencuentro con Adriano Celentano para celebrar los 40 años de ambos en la profesión. Atrás habían quedado los urlatori y se unían para publicar en 1998 Mina Celentano, uno de los álbumes más vendidos en la historia de ambos, gracias, entre otras cosas, a la portada, libreto interior e incluso videoclip que contaba la historia del reencuentro con los dos protagonistas caricaturizados por Gianni Ronco como el pato Donald y Daisy. Además, el libreto añadía, por primera vez, fotos de Mina en el estudio de grabación; volvíamos a verla en unas imágenes que marcarán la caracterización de la artista a partir de este momento
- pelo rojizo larguísimo recogido en una trenza, gafas de sol oscuras, pañuelo al cuello y negro omnipresente. Debido al éxito de este álbum, en Navidad de ese mismo año se puso en circulación una reedición, de título Buon Natale, de idéntico contenido musical, en cuya portada Daisy-Mina y Donald-Celentano se abrazan sentados en un sillón delante de la chimenea y el árbol de navidad. Era una manera de celebrar el éxito del proyecto y de incentivar unas ventas que habían sido ya más que satisfactorias.

\subsection{La PRIMERA DÉCADA DEL NUEVO SIGLO}

Los primeros proyectos de Mina para el nuevo milenio son dos álbumes temáticos muy especiales: Dalla terra, en 2000 y Sconcerto en 2001. El primero es una colección de música sacra y el segundo un homenaje a Domenico Modugno. Hasta 2002 no escucharemos nuevas composiciones, las de Veleno. Para este regreso, Mina se rodea de la élite de la canción italiana de autor: Zucchero, Renato Zero, Daniele Silvestri, o Samuele Bersani, entre otros. Un disco cargado de "veneno" en las composiciones presentado por una imagen de portada de la cantante en primer plano muy al estilo Cruella de Vil, la malvada de los 101 dálmatas. En el año 2003 se produce otro hecho curioso. La revista Vanity Fair empieza a publicar su edición italiana, de tirada semanal y sorprende a todos, en la última página, con una sección llamada C’è Mina per voi, a la que se añade el subtítulo "la più inafferrabile delle star risponde alle vostre domande". Se trata, pues, de un clásico consultorio donde los lectores se comunican con ella y ella responde a sus cartas preferidas. La sección va acompañada cada semana de una ilustración de Gianni Ronco donde siempre vemos a una pequeña Mina caricaturesca viéndoselas con la imagen de una gran Mina más canónica. Solo estas ilustraciones serían material suficiente para otro estudio.

En 2005 llegan dos de los discos más alabados de los últimos años. En enero se publica Bula Bula, título que hace referencia a la "isla mágica" de la cantante, a su lugar ideal, un lugar mental en el que se refugia cuando quiere escapar. Para ello, Balletti dibujó una puesta de sol y a una Mina que se pasea junto a un pequeño elefante que la sigue asido a su larguísima trenza. En noviembre del mismo año llegó a las tiendas un nuevo disco de versiones, volviendo a la tradición de los dos discos anuales. L'allieva es un disco tributo a Frank Sinatra, a quien Mina había homenajeado en discos anteriores pero no de manera temática. Para este homenaje, la cantante echó mano de su catálogo fotográfico familiar y la carátula nos enseñaba a una Mina niña que acaba de escribir algo - el título del disco - en la pizarra escolar. En 2006 se publicó otro álbum de canciones inéditas, Bau, un disco creado en estrecha colaboración con el cantautor boloñés Andrea Mingardi, que bromeaba citando a Mina cuando explicaba que el título del álbum, que es la onomatopeya del perro en italiano, se trata en realidad del acrónimo de la frase "Bravo Andrea, uniamoci!" Para la carátula, 
Mina, encantada con el trabajo de Gianni Ronco para su sección en Vanity Fair, vuelve a contar con una ilustración suya que recoge esa "nueva" imagen de Mina trabajando en el estudio que habían inaugurado las fotos del proyecto Mina Celentano. Boca enorme delante del micrófono, garganta cubierta por pañuelo negro, enormes gafas oscuras, enormes manos en movimiento - guiño a esas primeras coreografías tan características de la cantante, y larguísima trenza, de nuevo.

Para el sucesivo disco de versiones esperaríamos un año. Todavía se publicó en septiembre de 2007 y es un regalo que la cantante quiso hacer al público hispano para quien Mina había desaparecido discográficamente décadas atrás. Se rodea de algunos compañeros en algunas de las canciones - Serrat, Bosé, Diego el Cigala - y revisita alguno de sus más recientes éxitos, cantados esta vez en español, además de alguna concesión a la galería - Parole, parole, precisamente, a dúo con el futbolista Javier Zanetti. Para esta revisión, Balletti decide hacer otro homenaje desde la portada del disco, esta vez a Luciano Tallarini, tomando como idea original la última portada que éste había creado para Mina, la del disco Catene. Así pues, vemos a una Mina más actual, en línea con las últimas ilustraciones de Ronco, que se refleja en un espejo donde sus ojos aparecen de un color diferente, simbolizando esa revisión traducida de temas propios. Pero, observando más atentamente, parece que la imagen reflejada sale fuera de los márgenes del espejo, como si Mina fuera una y muchas a la vez, como si la capacidad de reinvención de la tigresa de Cremona no tuviera límites.

\section{ANTE UNA NUEVA DÉCADA}

Somos testigos del final de una nueva década. En 2001 el mundo no se ha acabado y tampoco las canciones de Mina, que cumple cuarenta años de carrera y lo celebra por todo lo alto. En febrero publica uno de sus proyectos más deseados, Sulla tua bocca lo dirò, que no es sino un homenaje al melodrama, un conjunto de arias de ópera y de clásicos de Broadway, con algún que otro capricho personal. El título del disco parafrasea una frase del aria Nessun dorma de la ópera Turandot de Puccini, que Mina se atreve a interpretar a pesar de tratarse de una pieza para hombre que toda Italia retiene en su memoria musical en la voz de Pavarotti. La misma ópera servirá a Balletti para la portada del disco, donde aparece un detalle del rostro de Mina caracterizada como la princesa Turandot en el cartel original de la ópera. El álbum se publicó en Estados Unidos con una versión completa de la carátula, quizá porque los ojos de Mina que miran tan penetrantemente desde la portada original italiana no son tan reconocidos por el público de ultramar. Después de una serie de cinco discos recopilatorios que conmemoran el aniversario de Mina bajo el título genérico de Riassunti d'amore, Mina cierra el año con Facile. Y, de nuevo, en los albores de una nueva década, nos hace una nueva declaración de intenciones; se rodea de algunos de sus colaboradores habituales y añade las plumas y las voces de algunos de los estandartes de la música contemporánea italiana Afterhours, Subsonica - para un disco de canciones directas pero no exactamente fáciles. Y de nuevo la portada de Balletti da en el clavo: sobre un fondo rosa chicle aparece la imagen de la cantante bocetada por un niño y reconocible, de nuevo, por los rasgos que hemos comentado a lo largo de nuestro recorrido por las máscaras de Mina: enormes ojos, la trenza y dos manos muy grandes en una de las cuales contamos - no por primera vez y no por casualidad, probablemente - seis dedos.

No sabemos si estamos asistiendo al inicio de una nueva era, pero desde luego sí a la enésima reinvención musical y gráfica de una artista única. Su último disco hasta el momento, Caramella, publicado en mayo de 2010, nos indica una línea de continuación con origen en Facile, y sabemos que están en creación nuevos inéditos y un disco acústico de éxitos de la canción italiana. O eso dicen. La propia Mina, desde Vanity Fair, ha dicho hace poco, ante la petición de un fan de que publique esa ingente cantidad de grabaciones que tendrá guardadas en los cajones de Lugano, su intención de mantenerlas ahí para una posible colección de volúmenes que se titularía Del mio peggio - haciendo referencia a la existente colección Del mio meglio. Una colección que vería la luz cuando ella ya no pudiese cantar, para seguir persiguiéndonos con lo que ella misma llama le mie canzonette. De alguna manera, cada canción, cada melodía, cada texto de Mina es, como decíamos, una declaración de intenciones. Y así lo cantaba en $\mathrm{Fa}^{\prime}$ qualcosa, tema que abría en 1973 el álbum Frutta e verdura: "Una donna puoi tradirla, non dimenticarla, come fai con me"Olvidar, olvidar, lo que se dice olvidar, a Mina, non è Facile.

\section{REFERENCIAS BIBLIOGRÁFICAS}

Bufacchi, M., Mina. 1958-2005. Ancora insieme, Roma, Editori Riuniti, 2005. Fratarcangeli, F., Mina. Parole ... parole ... parole..., Roma, Arcana edizioni, 2008. ----, Mina talk. Vent'anni di interviste (1959-1979), Roma, Coniglio editore, 2009. 